\title{
Biological Therapy in IBD-Is There Any Optimal End Point?
}

\author{
Klaudia Farkas, Tamás Molnár* \\ First Department of Medicine, University of Szeged, Szeged, Hungary \\ Email: *molnar.tamas@med.u-szeged.hu
}

Received 7 April 2014; revised 11 May 2014; accepted 18 May 2014

Copyright (C) 2014 by authors and Scientific Research Publishing Inc.

This work is licensed under the Creative Commons Attribution International License (CC BY). http://creativecommons.org/licenses/by/4.0/

c. (i) Open Access

\begin{abstract}
Biological therapy has been used in the treatment of inflammatory bowel disease (IBD-Crohn's disease [CD], ulcerative colitis [UC]) for more than a decade. Although guidelines exist on how to start and adjust biological therapy, information on when and how it should be stopped is still scarce. In this review, our aim is to summarize the results of the recently published papers on the outcome of the discontinuation of biological therapy in patients with CD and UC.
\end{abstract}

\section{Keywords}

\section{Crohn's Disease, Ulcerative Colitis, Biological Therapy, Discontinuation}

\section{Introduction}

Biological therapy has been used in the treatment of inflammatory bowel disease (IBD-Crohn's disease [CD], ulcerative colitis [UC]) for more than a decade. Biological therapies are indicated in steroid-refractory, steroiddependent and/or immunomodulator-refractory IBD and in patients intolerant to these conventional therapies. Patients who responded to an induction regimen with anti-tumor necrosis factor (TNF) therapy should be considered for scheduled re-treatment with or without concomitant immunomodulators.

Despite the detailed guidelines about the indication and the use of biological therapy, the very important question about the optimal time of its discontinuation is still scarce. There is no published evidence that definitely recommends how and when biologicals should be stopped and even less information is available on UC than that on CD. The costs, reliable increased risk of infectious and malignant diseases highlight the importance of the duration of maintenance biological therapy.

This review aims to summarize the results of the recently published papers on the outcome of the discontinuation of biological therapy in patients with CD and UC. PubMed was searched for all studies published the out-

*Corresponding author.

How to cite this paper: Farkas, K. and Molnár, T. (2014) Biological Therapy in IBD-Is There Any Optimal End Point? Health, 6, 1296-1299. http://dx.doi.org/10.4236/health.2014.611158 
come of discontinuation of infliximab and adalimumab therapy using the medical subject headings "ulcerative colitis”, “Crohn’s disease”, “infliximab”, “adalimumab”, “biological therapy”, “stop”, “discontinuation”. Only studies directly analyzing the outcome of the discontinuation of anti TNF- $\alpha$ therapy were eligible for inclusion.

\section{Studies on the Discontinuation of Biological Therapy}

In a Belgian study from 2009, 110 CD patients stopped infliximab after $>6$ months in remission. The median time to relapse was 47.3 months and $84 \%$ relapsed within 5 years. Only $16 \%$ of patients maintained remission completely off all medications [1]. A decrease in elevated baseline C-reactive protein (CRP) levels back to normal values $(<3 \mathrm{mg} / \mathrm{l})$ after initiation of infliximab treatment was significantly associated with a better outcome of infliximab treatment in the long term.

The study by Waugh et al. assessed the proportion of CD patients who obtained infliximab-induced remission and who relapsed after infliximab discontinuation [2]. The mean duration of the therapy was 15.6 months. 50\% of patients relapsed within 477 days, while 35\% remained in sustained clinical remission for nearly 7 years [2]. However, they could not identify factors predicting the outcome of the discontinuation of the therapy.

The statement of the World Congress of Gastroenterology was published in 2011. According to this, the withdrawal of therapy is recommended in patients with $C D$ who exhibit both complete mucosal healing and no biological evidence of inflammation [3]. However, no recommendation was made for UC.

The Infliximab diScon Tinuation in CrOhn's disease patients in stable Remission on combined therapy with Immunosuppressors (STORI) study is the largest trial examining the proportion and the risk factors of disease recurrence after discontinuation of successful biological therapy in CD [4]. Infliximab therapy was terminated in 115 patients in clinical remission after treatment with combined scheduled infliximab and a stable dose of immunosuppressant for at least one year. The mean duration of infliximab therapy was 2.2 years. Forty-five percent of patients relapsed following withdrawal of infliximab. Factors predicting time-to-relapse included: male sex, the absence of previous surgical resection, steroid treatment in the previous $6-12$ months, a Crohn's Disease Index of Severity (CDEIS) score $>0$, leukocyte count $>6.0 \times 10^{9} / \mathrm{L}$, hemoglobin $\leq 145 \mathrm{~g} / \mathrm{L}$, a CRP level $\geq 5.0 \mathrm{mg} / \mathrm{L}$, and fecal calprotectin $\geq 300 \mu \mathrm{g} / \mathrm{g}$ [4]. Re-treatment with infliximab was effective and well tolerated in $88 \%$ of patients who experienced a relapse. The high remission rate was sustained at least up to the third re-treatment infusion with no significant decrease in infliximab trough levels as compared with baseline and no formation of anti-infliximab antibodies.

Steenholdt et al. revealed that $61 \%$ of CD patients, and $75 \%$ of UC patients with clinical steroid-free remission at the time of stopping infliximab remained in remission 1 year after discontinued the drug [5]. Longer disease duration was associated with relapse in CD but predictive factors for relapse in UC could not be shown. The time from discontinuation of infliximab until half of the patients had experienced relapse was approximately 3.5 years in patients with UC and approximately 2 years in patients with CD. Although it did not reach statistical difference, maintenance of remission after infliximab discontinuation was longer inpatients with UC. 96\% of CD patients and $71 \%$ of UC patients obtained complete clinical remission at retreatment, remission generally occurred within the induction infusions.

In a study from Italy, Armuzzi and colleagues reported that 39\% of patients from their infliximab treated-cohort were able to discontinue the drug in remission and maintain this remission for a median of 13 months [6].

Our data about the disease course and frequency of relapse of CD and UC patients following discontinuation of one-year period of biological therapy in patients with remission was reported in [7] [8], 2013. One hundred twenty-one CD patients who had achieved clinical remission following one-year of biological therapy (87 infliximab, 34 adalimumab) and for whom biological therapy was then discontinued was followed up for a year. Biological therapy was restarted within 6 months of treatment cessation in $45 \%$ of patients. Logistic regression analysis revealed previous biological therapy and dose intensification to be in association with the need to restart biological therapy in CD patients. Smoking, steroid use and elevated CRP at the start of the one-year biological therapy, and also female gender also appeared to have an effect that was, however, not statistically significant. Retreatment of patients with biologicals was effective and well tolerated in $50 \%$ of patients. Our results suggested that, in the presence of the above predictors, biological therapy should probably be continued for more than one year. In case of UC, our data revealed $35 \%$ of the 51 patients needed to be retreated with infliximab within 4 month after treatment cessation [8]. Every patient has been in clinical remission following one-year of infliximab therapy. Only previous biological therapy was associated with the need of restarting infliximab. 
Table 1. Studies examining the outcome of the discontinuation of biological therapy.

\begin{tabular}{|c|c|c|c|c|c|c|}
\hline & Disease type & $\begin{array}{l}\text { Number of } \\
\text { enrolled } \\
\text { patients }\end{array}$ & $\begin{array}{l}\text { Number of } \\
\text { patients stopping } \\
\text { biologicals }\end{array}$ & $\begin{array}{l}\text { Treatment } \\
\text { period } \\
\text { (months) }\end{array}$ & $\begin{array}{l}\text { Median } \\
\text { follow-up } \\
\text { (months) }\end{array}$ & $\begin{array}{l}\text { Rate and duration of } \\
\text { remission }\end{array}$ \\
\hline Schnitzler, F. & CD & 614 & 110 & 6.2 & 53 & 47, 3 months \\
\hline Waugh et al. & CD & 100 & 48 & 15.6 & 84 & $35 \%$ for 7 years \\
\hline Louis et al. & CD & 125 & 115 & 26 & 28 & $54.8 \%$ during 1 year \\
\hline Steenholdt et al. & CD & 316 & 53 & u.n & 17.6 & $61 \%$ after a median of 2 years \\
\hline Steenholdt et al. & UC & 316 & 28 & u.n & 28.9 & $75 \%$ after a median of 2 years \\
\hline Molnar, T., et al. & CD & - & 121 & 12 & 12 & $55 \%$ during 1 year \\
\hline Farkas, K., et al. & UC & - & 51 & 12 & 12 & $65 \%$ during 1 year \\
\hline
\end{tabular}

Clinical remission was again achieved in $94 \%$ of those who restarted infliximab therapy, whereas $6 \%$ of the patients underwent surgery. Table 1 summarizes the main results of the studies examining the outcome of the discontinuation of biological therapy.

\section{Discussion}

There are clear criteria for starting biological therapy, although it is unclear when treatment should be stopped. Deciding when and which patient is candidate for stopping biological therapy without any risk of relapse or complication is going to be more and more important.

However, there are two sides of every question. It is true that there is currently no good reason to stop antiTNF therapy in patients who are in biological therapy-induced stable remission and can tolerate the therapy well, although it is not known whether the behavior of disease is altered in the longer term. However, potential long term side effects and the costs of therapy should not be forgotten, and benefit risk ratio should be assessed when we continue the therapy. It is also obvious that determination of predictors of a low risk of relapse when stopping the drug would also be useful. However, it seems that the duration of biological therapy in the previous studies - even in the STORI trial—was not enough to maintain sustained remission.

Prospective studies are needed to adequately assess long term evolution, disease outcome, safety and cost of strategies if biological therapy is ceased and used for long time. Potential consequences of discontinuation should be discussed with individual patients and the decision of discontinuation should be made on the basis of an individual judgment of benefits versus risks and cost-effectiveness until the results of randomized trials would not provide the answers on the questions. On the basis of the previous data, we think that patients who are treated with biologicals for years, achieve both steroid-free deep remission and mucosal healing, show normal CRP level, and did not need dose intensification ever, do not smoke and did not have previous intestinal resection are the most suitable candidate for stopping biologicals.

\section{Acknowlegements}

This work was supported by TAMOP-4.2.2.A-11/1/KONV-2012-0035, TAMOP-4.2.2-A-11/1/KONV-20120052 TAMOP-4.2.2.A-11/1/KONV-2012-0073 and OTKA PD 105948 (PI: KlaudiaFarkas).

\section{Conflict of Interest}

No conflict of interest exist.

\section{References}

[1] Schnitzler, F., Fidder, H., Ferrante, M., Schnitzler, F., Fidder, H., Ferrante, M., Noman, M., Arijs, I., Van Assche, G., Hoffman, I., Van Steen, K., Vermeire, S. and Rutgeerts, P. (2009) Long-Term Outcome of Treatment with Infliximab in 614 Patients with Crohn's Disease: Results from a Single-Centre Cohort. Gut, 58, 492-500. 
http://dx.doi.org/10.1136/gut.2008.155812

[2] Waugh, A.W., Garg, S., Matic, K., Gramlich, L., Wong, C., Sadowski, D.C., Millan, M., Bailey, R., Todoruk, D., Cherry, R., Teshima, C.W., Dieleman, L. and Fedorak, R.N. (2010) Maintenance of Clinical Benefit in Crohn’s Disease Patients after Discontinuation of Infliximab: Long-Term Follow-Up of a Single Centre Cohort. Alimentary Pharmacology \& Therapeutics, 32, 1129-1134. http://dx.doi.org/10.1111/j.1365-2036.2010.04446.X

[3] D’Haens, G.R., Panaccione, R., Higgins, P.D., Vermeire, S., Gassull, M., Chowers, Y., Hanauer, S.B., Herfarth, H., Hommes, D.W., Kamm, M., Löfberg, R., Quary, A., Sands, B., Sood, A., Watermeyer, G., Lashner, B., Lémann, M., Plevy, S., Reinisch, W., Schreiber, S., Siegel, C., Targan, S., Watanabe, M., Feagan, B., Sandborn, W.J., Colombel, J.F. and Travis, S. (2011) The London Position Statement of the World Congress of Gastroenterology on Biological Therapy for IBD with the European Crohn's and Colitis Organization: When to Start, When to Stop, Which Drug to Choose, and How to Predict Response? The American Journal of Gastroenterology, 106, 199-212. http://dx.doi.org/10.1038/ajg.2010.392

[4] Louis, E., Mary, J.Y., Vernier-Massouille, G., Grimaud, J.C., Bouhnik, Y., Laharie, D., Dupas, J.L., Pillant, H., Picon, L., Veyrac, M., Flamant, M., Savoye, G., Jian, R., Devos, M., Porcher, R., Paintaud, G., Piver, E., Colombel, J.F., Lemann, M. and Groupe D'etudes Thérapeutiques Des Affections Inflammatoires Digestives (2012) Maintenance of Remission among Patients with Crohn's Disease on Antimetabolite Therapy after Infliximab Therapy Is Stopped. Gastroenterology, 1, 63-70. http://dx.doi.org/10.1053/j.gastro.2011.09.034

[5] Steenholdt, C., Molazahi, A., Ainrworth, M.A., Brynskov, J., Østergaard Thomsen, O. and Seidelin, J.B. (2012) Outcome after Discontinuation of Infliximab in Patients with Inflammatory Bowel Disease in Clinical Remission: An Observational Danish Single Center Study. Scandinavian Journal of Gastroenterology, 47, 518-527. http://dx.doi.org/10.3109/00365521.2012.660541

[6] Armuzzi, A., Marzo, M., Felice, C., et al. (2010) Long-Term Scheduled Therapy with Infliximabin Inflammatory Bowel Disease: A Single-Centre Observational Study. Gastroenterology, 5, S691-692.

[7] Molnár, T., Lakatos, P.L., Farkas, K., Nagy, F., Szepes, Z., Miheller, P., Horváth, G., Papp, M., Palatka, K., Nyári, T., Bálint, A., Lőrinczy, K. and Wittmann, T. (2013) Predictors of Relapse in Patients with Crohn's Disease in Remission after 1 Year of Biological Therapy. Alimentary Pharmacology \& Therapeutics, 37, 225-233. http://dx.doi.org/10.1111/apt.12160

[8] Farkas, K., Lakatos, P.L., Nagy, F., Szepes, Z., Miheller, P., Papp, M., Palatka, K., Bálint, A., Bor, R., Wittmann, T. and Molnár, T. (2013) Predictors of Relapse in Patients with Ulcerative Colitis in Remission after One-Year of Infliximab Therapy. Scandinavian Journal of Gastroenterology, 48, 1394-1398.

http://dx.doi.org/10.3109/00365521.2013.845906

\author{
Abbreviations \\ C-reactive protein-CRP \\ Crohn's disease-CD \\ Crohn's Disease Index of Severity-CDEIS \\ Inflammatory bowel disease-IBD \\ Infliximab diScon Tinuation in CrOhn's disease patients in stable Remission on combined therapy with \\ Immunosuppressors-STORI \\ Tumor necrosis factor-TNF \\ Ulcerative colitis-UC
}

